\title{
Respons guru terhadap pengembangan bahan ajar quipper school pada materi perubahan lingkungan untuk meningkatkan manajemen pembelajaran guru

\section{Miftahul Khairani ${ }^{1,}{ }^{*}$, Slamet Suyanto ${ }^{2}$}

Pendidikan Biologi, Pascasarjana, Universitas Negeri Yogyakarta, Indonesia

${ }^{1}$ miftahulkhairani92@gmail.com *, ${ }^{2}$ slamet_suyanto@uny.ac.id

* Korespondensi penulis

\begin{tabular}{|c|c|}
\hline Informasi art & ikel \\
\hline Riwayat artike & \\
\hline Diterima & 31 Januari 2019 \\
\hline Revisi & 24 Mei 2019 \\
\hline Dipublikasikan & 2 Juni 2019 \\
\hline Kata kunci: & \\
\hline Quipper schoc & \\
\hline Perubahan lin & kungan \\
\hline Manajemen & nbelajar \\
\hline
\end{tabular}

\section{Keyword:}

Quipper school

Environmental change

Learning management

\begin{abstract}
ABSTRAK
Quipper school merupakan bahan ajar yang dapat membantu bagi para guru untuk melaksanakan proses belajar mengajar dan sudah banyak digunakan secara mendunia. Penelitian ini bertujuan untuk: a). Mengetahui kelayakan bahan ajar quipper school dalam meningkatkan manajemen pembelajaran guru; dan b). Mengetahui respons guru terhadap penggunaan bahan ajar quipper school dalam proses pembelajaran. Metode dalam penelitian ini menggunakan metode DDR (Design and Development Research) yaitu penelitian yang dimulai dengan mendesain, mengembangkan, dan mengevaluasikan dengan tujuan menciptakan produk yang diinginkan. Penelitian ini dilakukan pada semester genap, pada bulan Maret hingga Mei 2018, tahun pelajaran 2017/2018 di SMA Negeri 1 Depok Yogyakarta, dan SMA Negeri 6 Yogyakarta. Instrumen yang digunakan dalam penelitian ini berupa lembar observasi dan angket. Hasil dari keseluruhan nilai skor akhir data menyatakan bahwa 90,97\% guru memberikan respons positif dan menyatakan sangat setuju terhadap penggunaan bahan ajar quipper school dalam meningkatkan manajemen pembelajaran.
\end{abstract}

\section{ABSTRACT}

Teacher responses to the development of quipper school teaching materials on environmental change topic to improve the teacher's learning management. Quipper school's teaching material is the latest innovation that is currently worldwide, so that with quipper school's teaching materials it can make it easier for teachers to carry out teaching and learning activities, which are not only done in the school environment, but can also be done outside of school. This study aims to: a) knowing the feasibility of quipper school teaching materials on environmental change material used in the learning process to improve teacher learning management; and b) knowing the teacher's response to the use of Quipper School teaching materials in the learning process. The method in this study using the DDR (Design and Development Research) method is a study that begins with designing, developing, and evaluating with the aim of creating the desired product. This research was conducted in even semester, from March to May 2018, 2017/2018 
school year in Depok 1 Public High School, and Yogyakarta 6 Public High School. The instruments used in this study were observation sheets and questionnaires. The results of the study stated that $90.97 \%$ of teachers gave a positive response and stated strongly agree with the use of Quipper School teaching materials in improving learning management.

This is an open access article under the CC-BY-SA license.

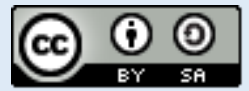

\section{Pendahuluan}

Bahan ajar quipper school merupakan bahan ajar yang berbasis e-learning yang memadukan antara bahan ajar yang bersifat kontinu dengan bantuan teknologi canggih sehingga memudahkan dalam proses pembelajaran (Husaefah \& Mardhiah, 2017; Pitagan, 2017; Wijayanti, 2016). Peneliti baik dalam maupun luar negeri banyak yang menggunakan bahan ajar quipper school karena merupakan suatu inovasi di dalam dunia pendidikan saat ini. Berdasarkan penelitian tersebut menyatakan bahwa dengan menggunakan bahan ajar quipper school dapat mempermudah guru dalam memberikan materi dan tugas kepada peserta didik (Mulyono, 2016; Saptani, 2016).

Bahan ajar quipper school merupakan salah satu media e-Learning, yang menggunakan Smartphone, Android, maupun komputer dengan bantuan akses internet ataupun kartu pradana berbayar dan dapat diakses setiap saat (Husaefah \& Mardhiah, 2017; Trisnaningsih \& Suyanto, 2016). Bahan ajar quipper school memiliki tiga fitur utama, yaitu: a) Qlink, bagian platform yang digunakan oleh guru untuk memantau perkembangan peserta didik, sehingga guru lebih efektif dalam memanfaatkan waktu yang dimiliki, memberikan dan mengoreksi tugas; b) Qcreate, bagian platform yang juga digunakan oleh guru menambahkan materi dan soal yang akan diunggah ke bagian qlearn pada peserta didik; dan c) Qlearn, bagian platform yang digunakan oleh peserta didik untuk mengakses materi dan soal yang diberikan guru.

Guru dapat menyediakan bahan ajar dan soal latihan, yang nantinya dapat digunakan oleh peserta didik untuk belajar mandiri. Melalui bahan ajar quipper school ini, guru dapat memantau peserta didik melalui dashboard, sehingga mengetahui mana peserta didik yang sudah membaca bahan ajar dan mengerjakan latihan secara keseluruhan, sebagian, dan yang belum mengerjakan (Bang, Chaowalit, \& Saekhow, 2016; Mulyono, 2016; Murthadha, 2017; Wijayanti, 2016). Guru dapat menindaklanjuti terhadap perkembangan peserta didik, ataupun memberi kesempatan bagi peserta didik untuk membaca bahan ajar dan latihan soal yang belum dikuasai.

Materi yang gunakan dalam bahan ajar quipper school adalah Perubahan lingkungan. Materi tersebut dibuat sedemikian menarik sehingga membuat peserta didik tertarik untuk mengikuti pembelajaran dengan menggunakan media quipper school. Materi yang dimuat di dalam bahan ajar quipper school berupa video dan berita mengenai kondisi lingkungan yang ada baik di Indonesia maupun luar negeri.

Perubahan lingkungan dapat terjadi akibat tindakan orang yang menimbulkan perubahan langsung atau tidak langsung secara fisik, kimia, dan hayati lingkungan hidup sehingga melampaui kriteria baku kerusakan lingkungan hidup ataupun akibat peristiwa alam (Indriatmoko \& Purwanta, 2017). Lingkungan dikatakan seimbang apabila jumlah energi yang masuk sama dengan energi yang keluar, atau pun seimbang antara komponen biotik dan abiotiknya. Suatu lingkungan memiliki kemampuan yang terbatas, kerusakan lingkungan yang serius menyebabkan kecilnya kemampuan lingkungan untuk kembali pada keseimbangan lingkungan. Dengan kata lain, kerusakan lingkungan yang cepat menyebabkan: 1) rendahnya daya dukung lingkungan, 2) mengecil atau hilangnya daya lenting lingkungan, serta 3) jauhnya terbentuknya keseimbangan lingkungan (Mulyanto, 2007; Noor, 2006).

Proses kegiatan belajar mengajar pada materi perubahan lingkungan, sangat 
membutuhkan manajemen pembelajaran yang baik. Manajemen pembelajaran yang tersusun dengan baik akan menghasilkan pembelajaran yang efektif dan efisien (Posselt, Böhme, Aymans, Herrmann, \& Kauffeld, 2016). Bicara mengenai manajemen pembelajaran tidak lepas kaitannya dengan peranan guru. Guru yang profesional harus memiliki keahlian dalam mengelola kelas, mengelola peserta didik, serta bagaimana melaksanakan pembelajaran agar menjadi lebih menyenangkan (Aedi, 2016; Aliyyah, 2011).

Pembelajaran pada kurikulum 2013 tidak hanya dilakukan di ruang kelas dengan kondisi yang sangat kaku antara guru dengan peserta didik tapi juga dapat dikombinasikan dengan pembelajaran $e$ learning yang di dalamnya terdapat peralatan pembelajaran, materi untuk memudahkan dalam mengelola pembelajaran dan aktivitas pembelajaran (Mtebe, 2015; Yusup, 2012). Fungsi lain manajemen pembelajaran adalah agar guru dapat menyesuaikan antara materi pelajaran yang akan disampaikan dengan kemampuan peserta didik dan penempatan waktu yang efektif. Melalui penggunaan bahan ajar quipper school, manajemen pembelajaran yang dinginkan guru mulai dari tahap perencanaan hingga evaluasi dapat terlaksana dengan baik. Manajemen sangat diperlukan untuk proses pembelajaran agar pembelajaran tidak berlangsung monoton, terutama dalam meningkatkan kemampuan prestasi belajar peserta didik (Landrum \& Kauffman, 2013; Levin, James; Nolan, 2014). Manajemen pembelajaran yang akan diukur pada penelitian ini adalah bagaimana seorang guru mengelola pembelajaran mulai dari perencanaan, pelaksanaan dan evaluasi menggunakan media bahan ajar quipper school pada hasil belajar. Instrumen pengukuran yang digunakan berupa angket.

Berdasarkan penjelasan tersebut, penelitian ini bertujuan: a) mengetahui kelayakan bahan ajar quipper school dalam meningkatkan manajemen pembelajaran guru dan b) mengetahui respons guru terhadap penggunaan bahan ajar quipper school dalam proses pembelajaran.

\section{Metode}

Penelitian ini menggunakan model pengembangan DDR (Design and Development Research), yaitu penelitian yang dimulai dengan: 1) Mendesain; yaitu merancang materi yang akan dibuat di dalam bahan ajar quipper school yang akan digunakan agar memiliki tampilan semenarik mungkin bagi peserta didik. 2) Mengembangkan; di tahap ini produk bahan ajar quipper school yang sudah dibuat di uji kepada guru dan peserta didik apakah sudah layak untuk digunakan sebagai bahan ajar dalam kegiatan belajar mengajar dalam meningkatkan manajemen pembelajaran guru. 3) Mengevaluasi; ditahap ini memperbaiki bahan ajar quipper school dari kritikan dan saran baik dari guru maupun peserta didik, dengan tujuan menciptakan produk yang di inginkan. Namun dalam penelitian ini peneliti hanya sampai pada tahap pengembangan saja tidak sampai tahap pengevaluasian. DDR termasuk dalam salah satu model penelitian Design Research (Ndongfack, 2015). Penelitian ini menghasilkan produk berupa bahan ajar quipper school. Penelitian ini dilakukan pada semester genap, bulan Maret hingga Mei 2018 tahun pelajaran 2017/2018 di SMA Negeri 1 Depok Yogyakarta dan SMA Negeri 6 Yogyakarta. Setiap sekolah diwakili oleh 2 orang guru Biologi. Instrumen yang digunakan dalam penelitian ini berupa lembar angket untuk menilai konten tampilan bahan ajar quipper school dan materi yang disampaikan dapat memudahkan manajemen pembelajaran guru, yang disusun berdasarkan aspekaspek yang akan diukur dalam proses penelitian, respons guru terhadap pengembangan bahan ajar quipper school dalam meningkatkan manajemen pembelajaran guru. Kriteria kelayakan angket tersebut dilihat berdasarkan kriteria: 76\% - 100\% (Sangat Setuju); 56\% - 75\% (Setuju); 40\% - 55\% (Kurang Setuju); 0\% - 39\% (Tidak Setuju).

\section{Hasil dan pembahasan}

Hasil pengembangan produk berdasarkan mode Design and Development Research (DDR) yang dikembangkan oleh Richey \& Klein. Pada penelitian pengembangan awal, hanya dilakukan sampai pada tahap validasi dengan uji coba skala kecil yang terdiri dari empat tahapan, yaitu: development, internal validation, exsternal validation, dan use.

Tahap pengembangan, pengembangan bahan ajar quipper school membutuhkan waktu selama 2 minggu berdasarkan storyboard yang telah disusun pada tahap desain. Secara spesifik pengembangan 
bahan ajar quipper school didasarkan pada kebutuhan sistem meliputi: software, hardware, dan komponen modul bahan ajar berbasis quipper school serta menggunakan pendukung software lain berupa web browser. Keunggulan bahan ajar quipper school di antaranya: a) mendukung pada perangkat komputer maupun mobile. b) bahan ajar quipper school bersifat user friendly. c) pada halaman quipper school peserta didik dapat membaca dan mengunduh materi, melihat video, tautan website eksternal, dan melihat animasi yang telah tersedia pada website pembelajaran tersebut. d) pada bahan ajar berbasis quipper school guru dapat memantau aktivitas masing-masing belajar peserta didik, menganalisis keaktifan, memantau diskusi, dan juga memberikan kesimpulan umum hasil diskusi.

Tahap validasi internal, pada tahap ini produk yang dikembangkan divalidasi secara internal. Validasi internal produk didasarkan pada tiga aspek, meliputi: 1) Aspek materi; berkaitan dengan kebenaran konsep yang dirumuskan. Materi yang digunakan dalam bahan ajar quipper school adalah perubahan lingkungan. 2) Aspek konstruksi; berkaitan dengan cara mengonstruksi bahan ajar, yang mencakup komponen: i) tema bahan ajar, ii) kompetensi dan indikator yang akan dicapai, iii) uraian materi pelajaran, iv) rangkuman dengan soal latihan, v) rubrik dan pedoman penskoran dari soal-soal latihan dan 3) Aspek bahasa; berkaitan dengan tingkat kekomunikatifan bahasa yang digunakan dalam media pembelajaran.

Tahap validasi eksternal, validasi external dalam penelitian ini melibatkan reviewer, yang terdiri dari reviewer ahli materi dan reviewer ahli media.

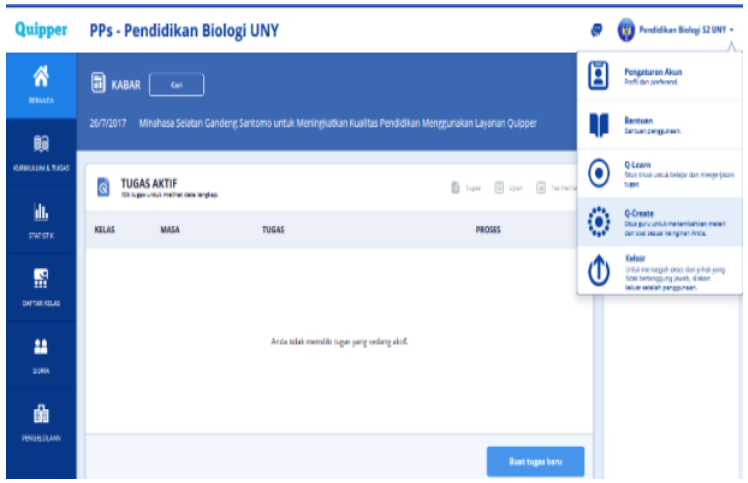

Gambar 1. Halaman awal portal guru pada quipper school

Tahap penggunaan, tahap penggunaan awal merupakan penerapan penggunaan bahan ajar quipper school pada pembelajaran Biologi di kelas dengan menggunakan metode belajar blended learning. Guru sebelum melakukan proses pembelajaran di kelas perlu mempersiapkan materi pada bahan ajar quipper school, tampilan yang sederhana portal guru (Gambar 1) memudahkan guru untuk melakukan desain manajemen pembelajaran.

Guru harus membuat desain pembelajaran dengan sebaik mungkin, kemampuan manajemen pembelajaran sangat penting untuk mendesain aktivitas pembelajaran sebelum melakukan proses pembelajaran dengan blended learning. Guru yang memiliki manajemen pembelajaran yang baik, maka guru tersebut dapat menjalankan proses pembelajaran dengan baik. Data yang diperoleh dari total rata-rata perhitungan nilai angket manajemen pembelajaran guru dengan menggunakan bahan ajar quipper school diperoleh hasil keseluruhan sebesar 90,97\% sangat setuju bahwa bahan ajar quipper school membantu guru meningkatkan manajemen pembelajaran, hal ini sejalan dengan penelitian (Suharyanto \& Mailangkay, 2016) Semakin intensif e-learning dimanfaatkan, maka mutu belajar peserta didik akan semakin meningkat pula.

Pemanfaatan website e-learning akan meningkatkan hasil belajar secara tidak langsung. Pembelajaran dengan menggunakan metode blended learning menjadikan peserta didik lebih memiliki bekal sebelum mengikuti pembelajaran di dalam kelas (Saifuddin, 2017). Bahan ajar quipper school yang digunakan memberi kemudahan bagi guru, untuk mengetahui mana peserta didik yang sudah membaca materi dan mengerjakan tugas (Gambar 2), sehingga guru dapat melakukan tindak lanjut terhadap peserta didik yang belum menyelesaikan tugas. Kegiatan ini terus dilakukan oleh guru mulai dari awal kegiatan pembelajaran hingga evaluasi.

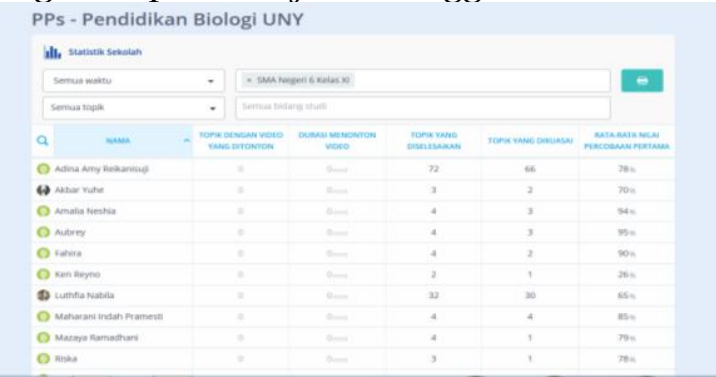

Gambar 2. Rekam aktivitas belajar peserta didik di quipper school 
Antusias belajar peserta didik meningkat ketika proses pembelajaran dipadukan dengan menggunakan bahan ajar quipper school. Supriani (2016) menyatakan bahwa quipper school dapat membuat peserta didik lebih mandiri dengan belajar menggunakan materi yang ada dalam bahan ajar quipper school. Peserta didik menjadi lebih aktif dalam kegiatan pembelajaran; dan menimbulkan semangat belajar mandiri bagi peserta didik. Lingkungan teknologi yang dikembangkan serta objek pembelajaran yang dipilih tersedia untuk peserta didik, sehingga sumber daya teknologi akan membantu dalam aktivitas belajar peserta didik (Wagner, Piovesan, Passerino, De Lima, \& De Castro Lozano, 2015). Adanya kemajuan belajar mandiri yang dimiliki peserta didik dengan menggunakan bahan ajar quipper school, ketika proses belajar mengajar di kelas memudahkan guru dalam menyampaikan informasi pelajaran pada peserta didik.

Guru dapat mengarahkan peserta didik untuk membaca dan mengerjakan tugas yang terdapat di bahan ajar quipper school dengan waktu yang telah disepakati bersama, sehingga memberikan kebebasan tersendiri bagi peserta didik. Peserta didik dapat membaca dan mengerjakan tugas yang diberikan guru melalui bahan ajar quipper school di mana saja dan kapan saja mereka bisa selama waktu yang ditentukan masih ada. Instruktur atau guru perlu untuk mendorong agar peserta didik belajar dan mengerjakan tugas di mana pun dan kapan saja (Kaplan, 2017). Hal tersebut memberikan antusias belajar yang tinggi bagi peserta didik untuk belajar lebih mandiri.

Manajemen pembelajaran guru dengan bahan ajar quipper school menggunakan metode pembelajaran blended learning, dapat dilihat pada Tabel 1 .

Tabel 1.Hasil aspek pengukuran manajemen pembelajaran guru

\begin{tabular}{ccccc}
\hline \multirow{2}{*}{$\begin{array}{c}\text { Aspek } \\
\text { Pengukuran }\end{array}$} & \multicolumn{4}{c}{ Pilihan Jawaban \% } \\
\cline { 2 - 5 } & STS & TS & S & SS \\
\hline $\begin{array}{c}\text { Perencanaan } \\
\text { Pengorganisa }\end{array}$ & 0,00 & 0,00 & 33,33 & 66,67 \\
$\begin{array}{c}\text { sian } \\
\text { Pelaksanaan }\end{array}$ & 0,00 & 0,00 & 31,25 & 68,75 \\
$\begin{array}{c}\text { Pengevaluasi } \\
\text { an }\end{array}$ & 0,00 & 4,55 & 36,36 & 59,09 \\
\hline
\end{tabular}

Berdasarkan Tabel 1 responden sangat setuju dengan proses perencanaan dengan menggunakan bahan ajar quipper school karena pelaksanaan pembelajaran di dalam kelas dapat menjadi lebih mudah dan sesuai dengan perencanaan. Dengan menggunakan bahan ajar quipper school dapat meningkatkan manajemen pembelajaran guru pada tahap perencanaan. Ke empat guru dari dua sekolah menyatakan bahwa guru lebih mudah mengatur kegiatan pembelajaran yang akan dilakukan selama 2 pertemuan terhadap materi perubahan lingkungan yang akan dilakukan.

Responden yang menyatakan aspek pengukuran pengorganisasian dalam manajemen pembelajaran guru dengan menggunakan bahan ajar quipper school diperoleh hasil data sebesar 68,75\% menyatakan sangat setuju dan 31,25\% menyatakan setuju. Ke empat guru tersebut menyatakan merasa terbantu dengan adanya bahan ajar quipper school dalam mengorganisasi kegiatan belajar mengajar karena guru bisa lebih mudah mengontrol untuk memberi penugasan pada peserta didik. Selain itu, guru juga merasa lebih mengetahui peserta didik yang sudah memahami materi yang telah disampaikan dan yang belum paham dengan melihat berdasarkan nilai akhir dan aktivitas yang dilakukan peserta didik pada bahan ajar quipper school. Hal ini sejalan dengan penelitian Ndongfack (2015) yang menyatakan bahwa kegiatan harus terkait dengan situasi kelas yang otentik untuk meningkatkan minat guru dalam program dan membuat pembelajaran menjadi menyenangkan.

Aspek pengukuran pelaksanaan dalam manajemen pembelajaran guru dengan menggunakan bahan ajar quipper school adalah sebanyak 59,09\% responden menyatakan sangat setuju, 36,36\% responden menyatakan setuju, dan $4,55 \%$ responden menyatakan tidak setuju. Menurut penilaian dari ke empat guru di dua sekolah untuk aspek pelaksanaan dalam manajemen pembelajaran menggunakan bahan ajar quipper school, tidak semuanya bisa dilakukan dengan menggunakan bahan ajar quipper school, karena untuk menggunakan bahan ajar quipper school ini ada kalanya memberikan waktu belajar yang tidak efektif ketika ada peserta didik yang tidak memiliki akses internet untuk mengakses quipper school yang berada di luar ruangan. Di sisi lain, Karmila dan Anggereni (2017) menyatakan 
bahwa pembelajaran dengan menggunakan bahan ajar quipper school dapat membantu guru pada beberapa aspek penilaian tertentu.

Penilaian aspek yang terakhir yaitu aspek evaluasi dalam manajemen pembelajaran dengan menggunakan bahan ajar quipper school diperoleh hasil data sebesar $75 \%$ responden menyatakan sangat setuju dan 25\% setuju. Hasil penilaian ke empat guru menyatakan dengan adanya bahan ajar quipper school guru lebih mudah dalam melihat kemajuan prestasi belajar peserta didiknya, walaupun hal tersebut tetap diikuti juga dengan pengevaluasian secara konvensional sejalan dengan penelitian Saptani (2016) menyatakan bahwa para peserta didik memiliki sikap positif terhadap penggunaan quipper school.

Berdasarkan total penilaian keseluruhan manajemen pembelajaran guru dengan menggunakan bahan ajar quipper school sebesar 90,97\% responden menyatakan sangat setuju. Hasil akhir keseluruhan dari penilaian angket terhadap bahan ajar quipper school, menyatakan bahwa bahan ajar quipper school dapat meningkatkan manajemen pembelajaran guru, terutama pada pembelajaran biologi materi perubahan lingkungan. Hal ini sejalan pernyataan bahwa dengan adanya bahan ajar berbasis quipper school memberikan pengaruh yang positif terhadap peningkatan manajemen pembelajaran guru dengan memanfaatkan teknologi yang sudah berkembang (Suharyanto \& Mailangkay, 2016) dan membantu guru dalam mengorganisasi proses kegiatan belajar mengajar lebih efektif sampai pada proses pengevaluasian peserta didik (Agustina \& Cahyono, 2017; Iguna, 2017).

\section{Simpulan}

Bahan ajar quipper school dengan materi perubahan lingkungan dapat meningkatkan manajemen pembelajaran guru, dibandingkan sebelum menggunakan bahan ajar quipper school dan guru memberikan respons yang sangat positif dalam proses pembelajaran.

\section{Referensi}

Aedi, N. (2016). Manajemen pendidikan \& tenaga kependidikan. Yogyakarta: Gosyen Publishing.
Agustina, E., \& Cahyono, B. Y. (2017). Perceptions of Indonesian teachers and students on the use of quipper school as an online platform for extended EFL learning. Journal of Language Teaching and Research, $8(4), \quad 794-800$. https://doi.org/ $10.17507 /$ jltr.0804.20

Aliyyah, R. R. (2011). Pengelolaan pendidik dan tenaga kependidikan. Lembaga Pengembangan dan Pemberdayaan Kepala Sekolah Surakarta.

Bang, S., Chaowalit, K., \& Saekhow, J. (2016). Effects of quipper school program based on local contents in Surat Thani province to enhance english listening skill of Matthayomsuksa V students. In Proceeding of ISER 42th International Conferences (hal. 4548). Tokyo, Japan.

Husaefah, H., \& Mardhiah, M. (2017). Application of e-learning quipper school. International Journal of Social Science and Humanities Research, 5(3), 522-526. Diambil dari http://www.researchpublish .com/journal/IJSSHR/Issue-3-July2017-September-2017/0

Iguna, S. (2017). Keefektifan media quipper school dan web blog untuk meningkatkan hasil belajar geografi pada kelas XI IIS di MAN Daerah Istimewa Yogyakarta. Geo Educasia, 2(4), 468-477. Diambil dari http://journal.student.uny.ac.id/ojs /ojs/index.php/geo-educasia/article /view/9981/9576

Indriatmoko, R. H., \& Purwanta, W. (2017). Perubahan lingkungan dan strategi adaptasi dampak perubahan iklim di bandar udara hasanuddin, Makassar. Jurnal Teknologi Lingkungan, 18(1), 80-87. Diambil dari http://ejurnal.bppt.go.id/index. $\mathrm{php} / \mathrm{JTL} /$ article/view/33/1503

Kaplan, D. E. (2017). Creative technology in the curriculum in online teacher training. Creative Education, 08(08), 1223-1235. https://doi.org/10.4236 /ce.2017.88087

Karmila, N., \& Anggereni, S. (2017). Pengaruh penggunaan pembelajaran quipper school terhadap minat belajar fisika siswa. Jurnal Pendidikan Fisika, 5(2), 120-127. Diambil dari http://journal.uin- 
alauddin.ac.id/index.php/Pendidika nFisika/article/view/3561/3979

Landrum, T. J., \& Kauffman, J. M. (2013). Behavioral approaches to classroom management. In C. M. Evertson \& C. S. Weinstein (Ed.), Handbook of Classroom Management: Research, Practice, and Contemporary Issues (hal. 1-28). New York: Routledge. https://doi.org/10.4324/97802038 74783.ch3

Levin, James; Nolan, J. F. (2014). Principles of classroom management: A professional decision-making model (7 ed.). New Jersey: Pearson. Diambil dari https://eric.ed.gov/?id=ED577 251

Mtebe, J. S. (2015). Learning management system success: Increasing learning management system usage in higher education in sub-Saharan Africa. International Journal of Education and Development using Information and Communication Technology, 11(2), 51-64. Diambil dari https://www.learntechlib.org/p/151 846/

Mulyanto, H. R. (2007). Ilmu lingkungan. Yogyakarta: Graha Ilmu.

Mulyono, H. (2016). Using quipper as an online platform for teaching and learning english as a foreign language. Teaching English with Technology, 16(1), 59-70. Diambil dari https://www.ceeol.com/search/ article-detail?id=408453\#details

Murthadha, M. (2017). Perbandigan penggunaan aplikasi quipper school dan edmodo terhadap hasil belajar pada materi jaringan hewan di kelas XI MIA SMA Negeri 11 Makassar. Universitas Islam Negeri Alauddin Makassar.

Ndongfack, M. N. (2015). Teacher Profession Development on Technology Integration Using the Mastery of Active and Shared Learning for Techno-Pedagogy (MASLEPT) Model. Creative Education, 06(03), 295-308. https://doi.org/10.4236/ce.2015.63 028

Noor, D. (2006). Geologi lingkungan. Yogyakarta: Graha Ilmu.

Pitagan, F. B. (2017). Quipper school contributes to higher test score, attendance rate and assignment submission in teaching mathematics. In DLSU Research Congress 2017. Manila: De La Salle University. Diambil dari https://www.dlsu.edu.ph/wp-conte $\mathrm{nt} /$ uploads/pdf/conferences/resear ch-congress-proceedings/2017/HC T/HCT-II-018.pdf

Posselt, G., Böhme, S., Aymans, S., Herrmann, C., \& Kauffeld, S. (2016). Intelligent learning management by means of multi-sensory feedback. Procedia CIRP, 54, 77-82. https://doi.org/10.1016/j.procir.20 16.05.061

Saifuddin, M. F. (2017). E-learning dalam persepsi mahasiswa. Jurnal VARIDIKA, 29(2), 102-109. https://doi.org/10.23917/varidika.v 29i2.5637

Saptani, D. A. (2016). Teachers' perception towards the use of quipper school in teaching english. In Proceedings of the Ninth International Conference on Applied Linguistics (CONAPLIN 9) (Vol. 82, hal. 233-235). Paris, France: Atlantis Press. https://doi.org/ 10.2991/conaplin-16.2017.51

Suharyanto, S., \& Mailangkay, A. B. L. (2016). Penerapan e-learning sebagai alat bantu mengajar dalam dunia pendidikan. Jurnal Ilmiah Widya, 3(4), 17-21. Diambil dari http://ejournal.jurwidyakop3.com/index.ph p/jurnal-ilmiah/article/view/261

Supriani, Y. (2016). Menumbuhkan kemandirian belajar matematika siswa berbantuan quipper school. Jurnal Ilmiah Pendidikan Matematika, 1(2), 210-220. https://doi.org/10.26877/jipmat.v1 i2.1248

Trisnaningsih, S., \& Suyanto, S. (2016). Pengembangan learning management system quipper school pada pembelajaran materi sistem pertahanan tubuh untuk meningkatkan motivasi dan hasil belajar siswa kelas XI di SMA Negeri 3 Yogyakarta. Jurnal Pendiidikan Biologi, 5(6), 28-36. Diambil dari http://journal.student.uny.ac.id/ojs /ojs/index.php/pbio/article/view/4 $600 / 4265$

Wagner, R., Piovesan, S., Passerino, L., De Lima, J. V., \& De Castro Lozano, C. (2015). MOOCs of inclusive technology in teacher education for 
vocational education. Creative Education, 06(17), 1832-1840. https://doi.org/10.4236/ce.2015.61 7187

Wijayanti, R. A. R. (2016). Peningkatan prestasi belajar siswa dengan bantuan penggunaan media quipper school. Jurnal Apotema, 2(1), 96104. Diambil dari https://stkippgri- bkl.ac.id/wp-content/uploads/2017 /04/D.-vol-2-no-1-jan-2016.pdf\# page $=104$

Yusup, P. M. (2012). Perspektif manajemen pengetahuan informasi, komunikasi, pendidikan, dan perpustakaan. Jakarta: Rajawali Press. 